\title{
Cryopreservation of spermatozoa of Mrigal, Cirrhinus cirrhosus with a view to minimize inbreeding and hybridization
}

\author{
M. R. I. Sarder, S. M. Rafiquzzaman ${ }^{1}$, R. Sultana and M. Faridul Islam \\ Department of Fisheries Biology \& Genetics, Bangladesh Agricultural University, Mymensingh-2202, Bangladesh \\ ${ }^{1}$ Freshwater Station, Bangladesh Fisheries Research Institute, Mymensingh-2200, Bangladesh
}

\begin{abstract}
To develop and standardize the cryopreservation protocol of $C$. cirrhosus sperm, a series of experiments were conducted. Seven extenders, egg-yolk citrate, urea egg-yolk, $0.9 \% \mathrm{NaCl}$, Kurokura-2, $\mathrm{M}^{\mathrm{a}}$ and $\mathrm{M}^{\mathrm{b}}$ and four cryoprotectants viz. DMSO, glycerol, methanol and ethanol were used to find out the suitable cryodiluent. Among the cryodiluents egg-yolk citrate with DMSO yielded (mean \pm SD) highest post-thaw motility $(83 \% \pm 5.70)$ that was closely followed by egg-yolk citrate with methanol (81\% \pm 6.51$)$ and urea egg-yolk with DMSO (79\% \pm 6.47$)$. Six dilution ratios such as 1: $2,1: 4,1: 7,1: 10,1: 15$, and 1: 20 (milt:cryodiluent) were used to determine the suitable milt dilution and found that sperm motility percentage increased roughly with the increase of dilution ratio. Different dilution ratios exhibited marked differences in the post-thaw spermatozoan motility $(P=0.000)$ and revealed that it has an interaction effect with the extenders $(P<0.05)$ but not with the cryoprotectants $(P>0.05)$. To determine the optimal cryoprotectant concentration, an increasing series of cryoprotectant concentrations from 5 to $30 \%(\mathrm{v} / \mathrm{v})$ were tested. DMSO at $10 \%$ concentration produced averagely highest post-thaw motility with all three extenders. Methanol and ethanol produced best result at $10 \%$ concentration but their lower $(<7 \%)$ and higher (>20\%) concentrations decreased spermatozoan motility.
\end{abstract}

Keywords: Mrigal, Cryopreservation, Spermatozoa, Inbreeding, Hybridization

\section{Introduction}

Fisheries sector is playing a vital role in the economy of Bangladesh with huge natural resources. Along with potential water resources, Bangladesh is also rich in the diversity of various fish species. It has ranked 3rd in aquatic biodiversity in Asia behind china and India, with approximately 300 species of fresh and brackish water species (Hussain and Mazid, 2001). It has already emerged as one of the leading nations in freshwater aquaculture production during recent years and its growth rate is quite comparable to that of China and India. The commonly used fast growing carp species for composite carp culture in the country are catla, rohu, mrigal, silver carp, grass carp and mirror/common carp.

Among Indian major carps, mrigal is an important species due to its relatively better taste and higher market price. Being a commercially important aquaculture fish, requirement of seed is meet up through induced breeding techniques in hatchery. Therefore, the species is being genetically introgressed by the hatchery manager either out of scientific interest or because of shortage of adequate hatchery population. Pure mrigal are severely being threatened by introgressive hybridization. Moreover, unplanned hybridization, inbreeding depression and genetic drifts have been the causes of deteriorating quality of this species. In this regard cryopreservation is the simplest and most inexpensive method to preserve genomes that can be used to maintain future conservation options. Establishment of germ plasm repository through cryopreservation is called cryogenic gene bank. As more fish species become threatened or endangered, it is reasonable to establish a regional fish germ plasm repository to preserve the vanishing genetic material as well as to conserve the existing gene pool. Cryopreservation of fish spermatozoa is relatively new compared to livestock semen preservation that is now applied in horse, poultry and cow for upgrading the native stock. Similarly this technique has immense applied value and it will become an important tool when programs are designed to produce special strains of superior fish stocks and also can easily mitigate or solve the inbreeding problem.

Although cryopreservation of fish sperm is a potential technique for improving quality seed production system, very few work has been done in Bangladesh so far. By standardizing a suitable cryopreservation protocol and establishing cryogenic gene bank good quality sperm could be supplied to both government and private hatcheries as required and thus, genetically improved carp seeds could be made available to the rural fish farmers. 


\section{Materials and Methods}

\section{Rearing of broodstock}

Male and female broods were collected from different sources (Halda river-origin and different hatcheries) and stocked in the ponds at the vicinity of Fisheries Faculty premises, Bangladesh Agricultural University, Mymensingh. Brood fish were reared with supplementary feed comprising of mustard oil cake, rice bran, wheat bran and fish meal two times a day at $5 \%$ of their total body weight. Vitamin-E was supplemented with the given feed to enhance the gonad development.

\section{Experimental design}

To develop and standardize the protocols for cryopreservation of Mrigal sperm four experiments were conducted. Determination of suitable extenders and cryoprotectants and their combinations was the first experiment. Finding out the suitable sperm: cryodiluent dilution ratio and concentration of cryoprotectant in the cryodiluent were the second and third experiments. Determine the effects of cryopreservation on fertilization and hatching of eggs was the fourth experiment. To carry out the first experiment the following procedures were maintained.

\section{Collection of milt}

Mature male with desired phenotypic characteristics were selected and induced by injecting PG extract to get sufficient amount of milt. Excess moisture, urine, gut extrudes and mucus were wiped from the area of the genital pore with absorbent paper. Gentle abdominal pressure was applied to collect the milt. Micropipette and tips were used at the time of collection of milt. The collected milt was transferred to eppendorfs or plastic tubes and stored on ice to prevent quality deterioration during further processing.

\section{Evaluation of sperm quality and}

After collection the quality of sperm was checked under microscope by placing $1-2 \mu$ diluted sperm on glass slide. Only samples containing more than $80 \%$ motile cells by eye-estimation were used for cryopreservation. The number of sperm per $\mathrm{ml}$ of milt was estimated using a haemacytometer counter. Counting of sperm is needed to standardize the degree of dilution of milt and to determine the density of sperm per straw for maintaining desired level of egg: sperm ratio during fertilization of eggs.

\section{Cryodiluents}

Dilution of sperm was done by adding cryodiluent to the milt sample at specified ratios. Cryodiluents consist of extenders and cryoprotectants. The extender is a solution that contains organic and inorganic chemicals which increase the efficacy of cryopreservation of sperm. Cryoprotectants are mixed with extender to protect the cell from damage during cooling and freezing. Six extenders namely egg-yolk citrate, urea-egg-yolk, Kurokura-2, $\mathrm{M}^{\mathrm{a}}, \mathrm{M}^{\mathrm{b}}$, and $0.9 \% \mathrm{NaCl}$ and four cryoprotectants viz. DMSO, glycerol, methanol and ethanol were used throughout the experiment. The chemical constitutions of these extenders are given in Table 1.

\section{Dilution and preparation of milt for cooling}

Pure milt is not suitable for freezing. So, collected milt was diluted with the cryodiluent (extender + cryoprotectant) at different ratios depending on the type of extender. For egg-yolk citrate, urea-egg yolk, $\mathrm{M}^{\mathrm{a}}$ and $\mathrm{M}^{\mathrm{b}}$ milt was diluted with the cryodiluent at a ratio of 1:4 (milt: cryodiluent), and for Kurokura-2 and $0.9 \% \mathrm{NaCl}$ solution, $1: 9$ dilution ratio was maintained. Cryodiluent was prepared by adding $10 \%$ cryoprotectant (e.g. DMSO, glycerol, ethanol and methanol) to $90 \%$ extender by volume. The milt and cryodiluent were kept on ice prior to dilution.

\section{Equilibration, filling and sealing of straws}

The diluted milt was equilibrated for $10 \mathrm{~min}$ at room temperature and the motility of the equilibrated sperm was checked under microscope before filling straws. Equilibrated milt sample was drawn into the straw and free end of the straw was sealed using heat. The straws were finally placed in the cryochamber and initiated cooling. 
Table 1. Chemical constitution of different extenders used for sperm cryopreservation of Cirrhinus cirrhosus

\begin{tabular}{|c|c|c|c|c|c|c|}
\hline Extender & I & II & III & IV & V & $\mathrm{VI}$ \\
\hline Constituent & $\mathrm{Ma}$ & $\mathrm{Mb}$ & Kurokura-2 & Urea-egg-yolk & Egg-yolk citrate & $0.9 \% \mathrm{NaCl}$ \\
\hline Sodium chloride & $730 \mathrm{mg}$ & $850 \mathrm{mg}$ & $360 \mathrm{mg}$ & $0.3 \%$ & $0.4 \%$ & \multirow{11}{*}{$\begin{array}{l}0.9 \mathrm{~g} \mathrm{NaCl} \\
\text { dissolved in } \\
100 \mathrm{ml} \text { distilled } \\
\text { water. }\end{array}$} \\
\hline Urea & & & & $0.4 \%$ & & \\
\hline Sodium citrate & & & & & $0.1 \%$ & \\
\hline Sodium bicarbonate & $500 \mathrm{mg}$ & $500 \mathrm{mg}$ & $20 \mathrm{mg}$ & \multirow{8}{*}{$\begin{array}{l}\text { Dissolved in } 100 \mathrm{ml} \text { of distilled } \\
\text { water. Pancromycin (1000 iu/ml) } \\
\text { and streptomycin (1000 iu/ml) } \\
\text { were added to the buffer solution. } \\
\text { Egg yolk was added to the buffer } \\
\text { at a ratio of } 1: 4 \text { (egg yolk: buffer). } \\
\text { Therefore, } 80 \mathrm{ml} \text { of buffer was } \\
\text { mixed with } 20 \mathrm{ml} \text { of egg yolk. }\end{array}$} & \multirow{8}{*}{$\begin{array}{l}\text { Dissolved in } 100 \mathrm{ml} \text { of distilled water. } \\
\text { Pancromycin }(1000 \quad \text { iu/ml) and } \\
\text { streptomycin }(1000 \quad \text { iu/ml) were } \\
\text { added to the buffer solution. Egg yolk } \\
\text { was added to the buffer at a ratio of } \\
\text { 1:4 (egg yolk: buffer). Therefore, } 80 \\
\text { ml of buffer was mixed with } 20 \mathrm{ml} \text { of } \\
\text { egg yolk. }\end{array}$} & \\
\hline Fructose & $500 \mathrm{mg}$ & & & & & \\
\hline Mannitol & $500 \mathrm{mg}$ & & _ & & & \\
\hline $\mathrm{CaCl} 2$ & & & $22 \mathrm{mg}$ & & & \\
\hline $\mathrm{KCl}$ & _ & 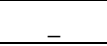 & $1000 \mathrm{mg}$ & & & \\
\hline $\mathrm{MgCl} 2$ & - & & $8 \mathrm{mg}$ & & & \\
\hline \multirow[t]{2}{*}{ Vegetable lecithin } & $750 \mathrm{mg}$ & $1500 \mathrm{mg}$ & - & & & \\
\hline & \multicolumn{3}{|c|}{ Dissolved in $100 \mathrm{ml}$ distilled water } & & & \\
\hline
\end{tabular}

\section{Freezing}

Computer controlled freezer ( $C L 300$ ) was used to freeze the samples using the following program. Two-step freezing method was applied where the milt was cooled from $+20^{\circ} \mathrm{C}$ to $-4^{\circ} \mathrm{C}$ at a rate of $4^{\circ} \mathrm{C}$ per minute, then from $-4^{\circ} \mathrm{C}$ to $-80^{\circ} \mathrm{C}$ at a rate of $10^{\circ} \mathrm{C}$ per minute and finally transferred into liquid nitrogen.

\section{Thawing}

Straws were retrieved from the LN dewar using tweezer and thawed in room temperature. One to two $\mu \mathrm{l}$ of post thawed milt sample placed on to glass slide and activated by adding conditioned water to assess the motility using microscope.

To determine the suitable dilution ratio twelve cryodiluents originated from three extenders such as egg-yolk citrate, urea-egg-yolk and $0.9 \% \mathrm{NaCl}$ and four cryoprotectants namely DMSO, glycerol, methanol and ethanol were tested. Collected milt was diluted with each of the cryodiluent at six different ratios such as 1: 2, 1: 4, 1: 7, 1: 10, 1: 15, and 1: 20. Other procedures such as milt collection, quality assessment, equilibration, freezing and thawing were same as experiment 1.

The effect of cryoprotectant concentration was tested using four cryoprotectants (DMSO, glycerol, methanol and ethanol) with each of the three extenders used in the experiment 2 . The cryoprotectants were used at $5,7,10,15,20$ and $30 \%(\% \mathrm{v} / \mathrm{v})$ of the extender and thereby, twenty four cryodiluents were generated from each extender.

\section{Statistical analysis}

Data were analysed using two-factor and three-factor ANOVA. Significant results (at $P<0.01$ and $P<$ 0.05 ) were further tested by Duncan's Multiple Range Test (DMRT) to separate means.

\section{Results and Discussion}

\section{Effect of extender and cryoprotectant on post-thaw motility of sperm}

In the first experiment, 24 experimental variants were tested to determine the combined effect of extender and cryoprotectant on the efficacy of cryopreservation of mrigal sperm. Motility of sperm was tested for all the experimental variants during post-thaw period. Statistical analysis showed significant difference $(P<0.01)$ among different extender and cryoprotectant and their combinations. A marked difference of spermatozoan motility was also observed between the equilibrium and post-thaw period (Fig. 1). The satisfactory results were recorded in case of egg-yolk citrate, urea egg-yolk and $0.9 \% \mathrm{NaCl}$, giving approximately $83 \%, 79 \%$ and $38 \%$ average post-thaw motility respectively (Table 2). Milt samples with $\mathrm{M}^{\mathrm{a}}$ and $\mathrm{M}^{\mathrm{b}}$ became coagulated and Kurokura-2 showed poor performance ( $<20 \%$ post-thaw motility). Among four cryoprotectants used, DMSO gave highest post-thaw spermatozoan motility with all the extenders. Methanol and ethanol gave very close results to DMSO 
and were more efficient than glycerol. The results of DMRT identified egg-yolk citrate (mean 78.50) and urea egg-yolk (mean 76.75) as most effective (Rank-A) among the extenders and DMSO as best cryoprotectant (Rank-A, mean 42.83).

Based on earlier studies (Chao et al., 1975; Withler, 1982; Shirohara et al., 1982) the dilution ratio of milt: cryodiluent was selected 1:4 for egg-yolk citrate, urea egg-yolk, $M^{a}$ and $M^{b}$ and 1:9 for Kurokura2 and $0.9 \% \mathrm{NaCl}$ during determination of suitable extender-cryoprotectant combination (Kumar, 1988 and 1989, Magyary et al., 2000). Cryoprotectant concentration was maintained $10 \%(\mathrm{v} / \mathrm{v})$ by volume in the trials as it was reportedly common and effective for many species (Chao et al., 1975; Withler, 1982; Shirohara et al., 1982). It was observed that egg-yolk citrate and urea-egg-yolk with $10 \%$ DMSO, methanol and ethanol produced best post-thaw motility, while glycerol failed to do this. As a cryoprotectant DMSO showed a good performance as like other previous studies (Rao, 1989), methanol and ethanol also exerted satisfactory performance. When egg-yolk is used as extender it acts as an extracellular cryoprotectant. Egg-yolk improves post-thaw motility because the low density lipoprotein fraction (LDL) associates with cell membranes and provides protection against injury during the cryopreservation process (Babiak et al., 2001). When DMSO is used as cryoprotectant it penetrates rapidly into the cellular membrane $($ Rao, 1989) and brings a quick balance in between the intra and extra-cellular fluid concentration. On the other hand, glycerol gave poor post-thaw motility because it penetrates slowly into the cell membrane (Harvey and Ashwood-Smith, 1982).

Coagulation of thawed milt was common for the extenders $\mathrm{M}^{\mathrm{a}}$ and $\mathrm{M}^{\mathrm{b}}$ with all the cryoprotectants. Several reasons have been attributed for these clump formation after thawing the stored milt. These are improper concentration of cryoprotectant (Withler, 1982) and inadequate concentration of the semen prior to their immersion in liquid nitrogen (Chao et al., 1975). The inorganic extender $0.9 \%$ $\mathrm{NaCl}$ and Kurokura-2 with 10\% DMSO exhibited low post-thaw motility. It was further deteriorated when these extenders mixed with methanol, ethanol and glycerol. The absence of egg-yolk in the cryodiluent might be responsible for this poor performance.

Table 2. Average post-thaw motility of sperm preserved with different combinations of extenders and cryoprotectants

\begin{tabular}{|c|c|c|c|}
\hline Extenders & Cryoprotectant & $\begin{array}{l}\text { Dilution ratio } \\
\text { (milt: diluent) }\end{array}$ & $\begin{array}{c}\% \text { Post-thaw motility } \\
\text { (mean } \pm \text { SD) }\end{array}$ \\
\hline \multirow{4}{*}{ Egg-yolk citrate } & DMSO & \multirow{4}{*}{$1: 4$} & $83 \pm 5.70$ \\
\hline & Glycerol & & $73 \pm 11.51$ \\
\hline & Methanol & & $81 \pm 6.51$ \\
\hline & Ethanol & & $77 \pm 6.71$ \\
\hline \multirow{4}{*}{ Kurokara-2 } & DMSO & \multirow{4}{*}{$1: 9$} & $45 \pm 25$ \\
\hline & Glycerol & & $2 \pm 4.47$ \\
\hline & Methanol & & $10 \pm 10$ \\
\hline & Ethanol & & $18 \pm 8.36$ \\
\hline \multirow{4}{*}{$M^{a}$} & DMSO & \multirow{4}{*}{$1: 4$} & $10 \pm 7.37$ \\
\hline & Glycerol & & 0 \\
\hline & Methanol & & 0 \\
\hline & Ethanol & & 0 \\
\hline \multirow{4}{*}{$M^{b}$} & DMSO & \multirow{4}{*}{$1: 4$} & $1 \pm 2.23$ \\
\hline & Glycerol & & 0 \\
\hline & Methanol & & $2 \pm 4.47$ \\
\hline & Ethanol & & 0 \\
\hline \multirow{4}{*}{ Urea egg- yolk } & DMSO & \multirow{4}{*}{$1: 4$} & $79 \pm 5.47$ \\
\hline & Glycerol & & $79 \pm 7.41$ \\
\hline & Methanol & & $73 \pm 4.47$ \\
\hline & Ethanol & & $76 \pm 8.21$ \\
\hline \multirow{4}{*}{$0.9 \% \mathrm{NaCl}$} & DMSO & \multirow{4}{*}{$1: 9$} & $38 \pm 37.41$ \\
\hline & Glycerol & & $9 \pm 13.03$ \\
\hline & Methanol & & $33 \pm 10.95$ \\
\hline & Ethanol & & $31 \pm 16.73$ \\
\hline
\end{tabular}




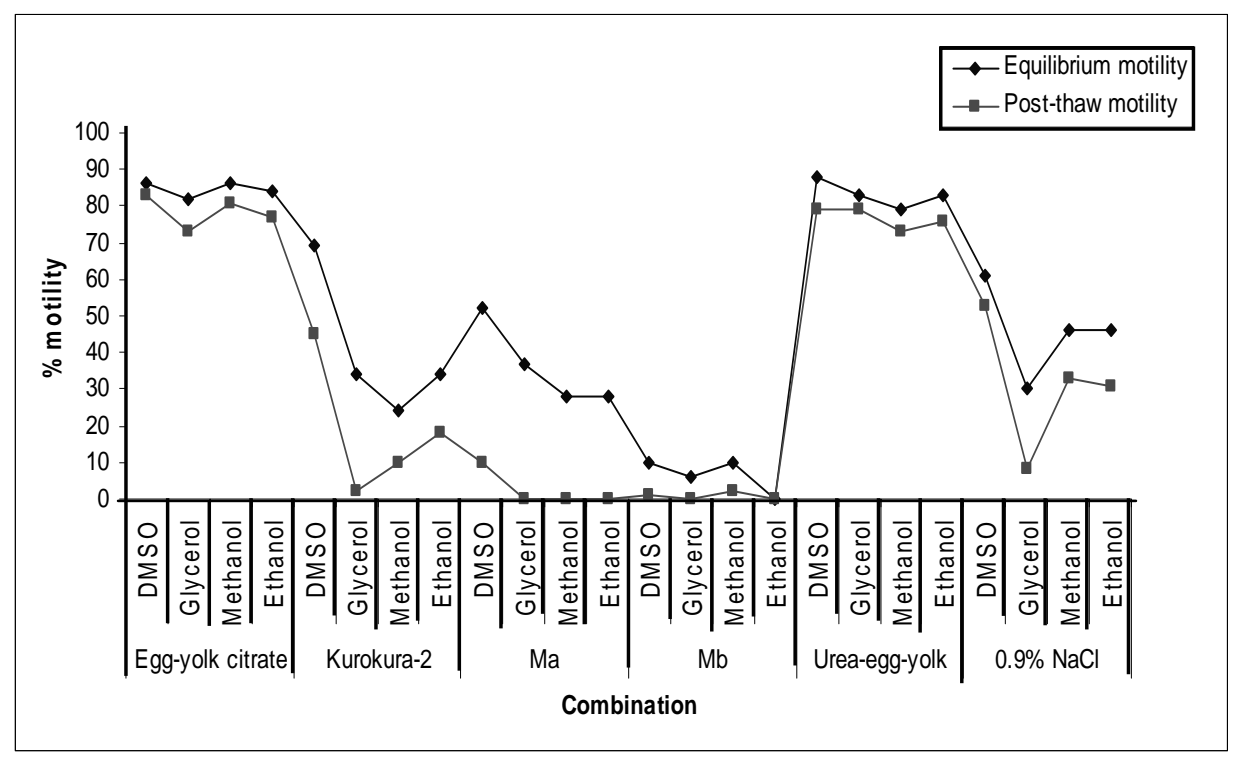

Fig.1. Relationship between equilibrium and post-thaw spermatozoan motility of C. cirrhosus at different combinations of extender and cryoprotectant

\section{Effect of dilution ratio on post-thaw sperm motility}

Successful cryopreservation depends not only on the right choice of extenders and cryoprotectants, but also on the suitable sperm: cryodiluent dilution ratio. In this experiment various ratios of milt and cryodiluent viz. 1:2, 1:4, 1:7, 1:10, 1:15, 1:20 were tested. The experiment was conducted with the three best performed extenders, egg-yolk citrate, urea egg-yolk and $0.9 \% \mathrm{NaCl}$. Corresponding data representing the effects of different dilution ratios with three extenders are given in Table 2 . The statistical analysis for the effects of different dilution ratios showed marked differences in the postthaw spermatozoan motility $(P=0.000)$ and revealed that it has an interaction effect with the extenders $(P<0.05)$ but not with the cryoprotectants $(P>0.05)$. It was observed that motility percentage increased roughly with the increase of dilution ratio (Fig. 2a-d). The best results were achieved from urea eggyolk (76.66\%), egg-yolk citrate (78.33\%) and $0.9 \% \mathrm{NaCl}(43.33 \%)$ with different cryoprotectants at the ratios of 1:20, $1: 7$ and $1: 4$ respectively.

When six dilution ratios between milt and cryodiluent were tested 1:7, 1:10, 1:15 and 1:20 responded well although there were differences between them. It also revealed that post-thaw motility of sperm was lower at 1:2 in most of the cases. Though glycerol produced poorest post-thaw motility at 1:2 dilution, it exhibited exceptionally better result at the dilution ratio of 1:20. Since glycerol is very dense and viscous in nature its higher dilution could reduce the viscosity and increase its permeability to cell. Bergeron et al. (2002) reported the best result at 1:15 dilution when walleye sperm was diluted at three dilution ratios 1:5, 1:9 and 1:15. Dreanno et al. (1997) found no significant effect on post-thaw motility when turbot sperm was diluted at the ratios of 1:1, 1:2, 1:4 and 1:9.

\section{Effect of cryoprotectant concentration on post-thaw motility}

This experiment was conducted to find out optimal cryoprotectant concentration in the cryodiluent using six different concentrations such as $5 \%, 7 \%, 10 \%, 15 \%, 20 \%$, and $30 \%$. It was observed that the effect of different cryoprotectant concentration on post-thaw motility varied with the type of cryoprotectant and their different concentration (ANOVA, $\mathrm{P}=0.000$ ). DMSO at $10 \%$ concentration produced averagely highest post-thaw motility with all three extenders. Similarly, $10 \%$ methanol and ethanol produced best result but both their lower $(<7 \%)$ and higher $(>20 \%)$ concentrations decreased spermatozoan motility. Higher concentration (>20\%) of DMSO was found to be inefficient, but glycerol with its higher concentration (>10\%) found effective with the extenders urea egg-yolk and egg-yolk citrate. The effective concentrations of DMSO, glycerol, methanol and ethanol that yielded highest motility after freezing and thawing with the extenders urea egg-yolk, egg-yolk citrate were $7 \%, 5 \%$, $10 \% ; 7 \%, 30 \%, 15 \% ; 7 \%, 10 \%, 15 \%$ and $20 \%, 7 \%, 10 \%$ respectively Fig (3a-c). 


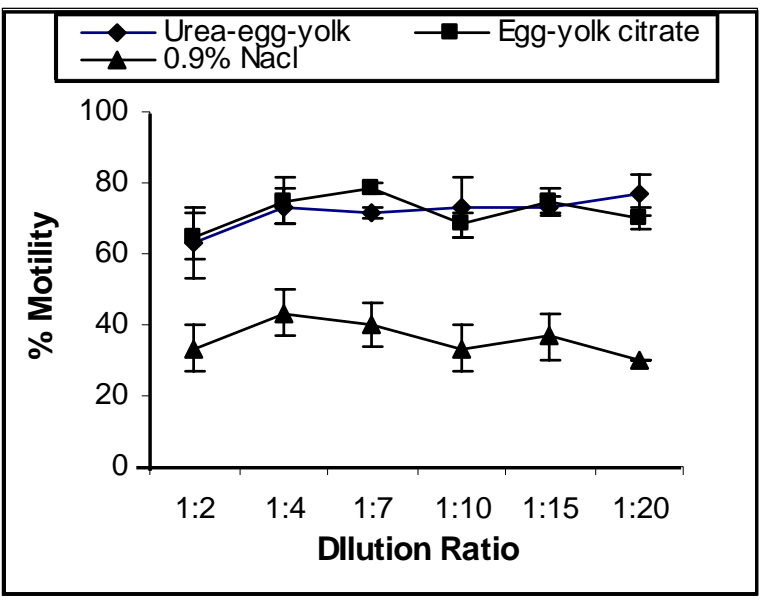

a

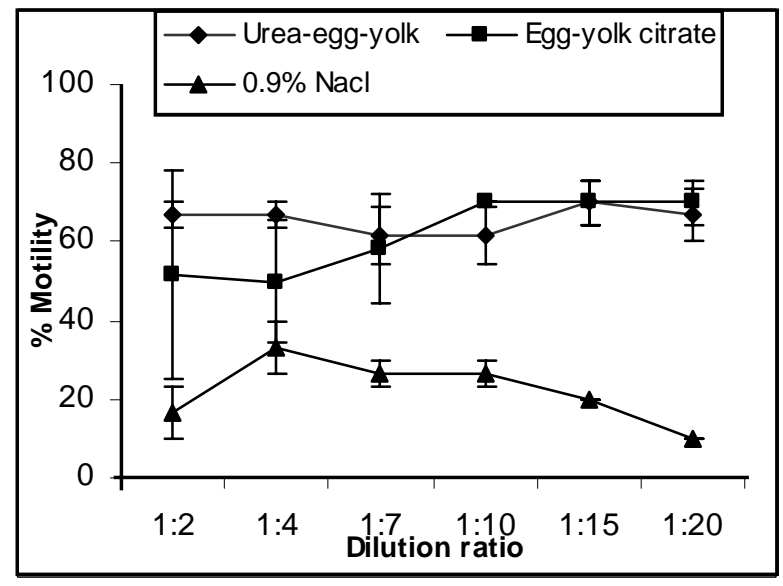

C

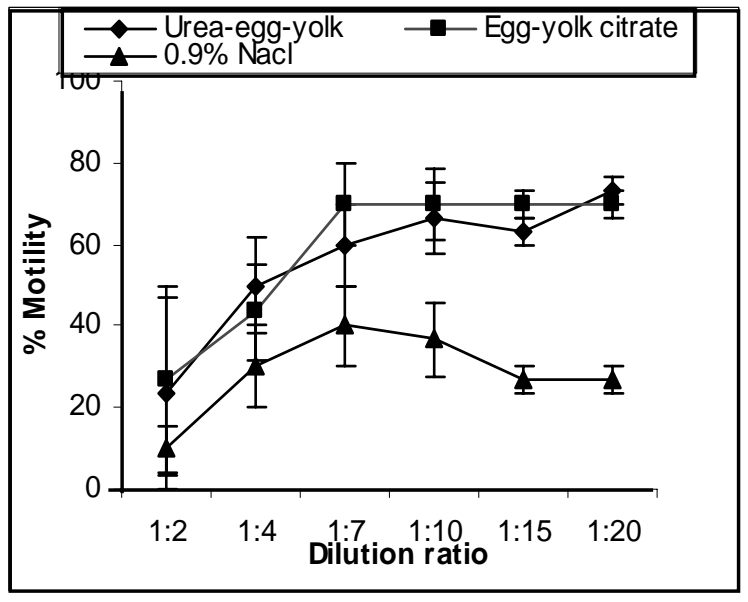

b

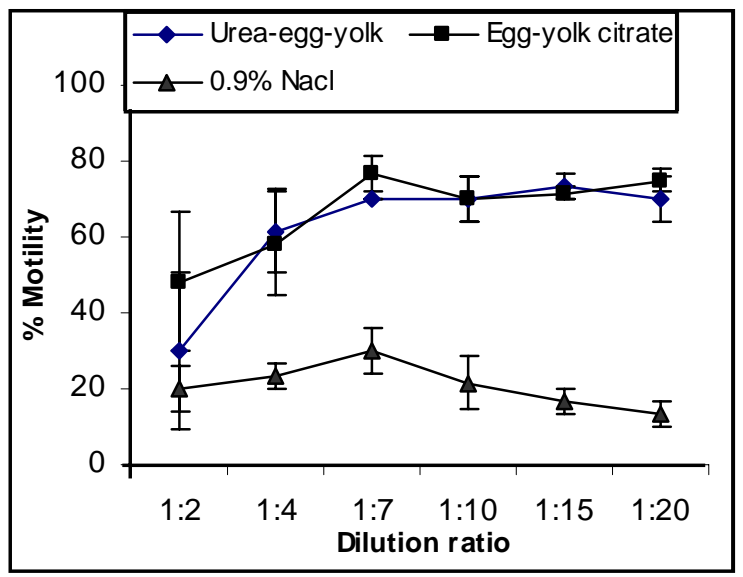

d

Fig. 2. Effects of different dilution ratios (milt: cryodiluent) on the viability of cryopreserved sperm of $C$. cirrhosus, (a) DMSO (b) glycerol (c) methanol (d) ethanol each with egg-yolk citrate, urea egg-yolk and $0.9 \% \mathrm{NaCl}$ solution. Each value (average \%motility) represents the data from three replicates

Cryoprotectants when used at different concentrations produced differential responses. DMSO, methanol and ethanol at $7 \%$ and $10 \%$ concentrations produced $80 \%$ post-thaw motility, which was highest among the six cryoprotectant concentrations. Leung (1987) reported best post-thaw motility of barramundi sperm at 5\% DMSO. Gwo et al. (1991) reported no significant differences in post-thaw fertility when $15 \%$ and $20 \%$ concentrations of DMSO were used to preserve Atlantic croaker spermatozoa. Higher concentration of cryoprotectant i.e. 30\% DMSO produced very little or even no post-thaw motility and in some cases $30 \%$ methanol and ethanol were found detrimental to sperm in the study. Similar assumption was postulated by Rana and McAndrew (1989) that motility could not be initiated in spermatozoa suspended in $30 \%$ and $40 \%$ methanol or DMSO. Apart from the three cryoprotectants, glycerol with low concentration was not found suitable but its $20 \%$ and $30 \%$ concentration provided best post-thaw motility with some extenders. Similar finding was reported by Piironen (1993) and opined that 20\% glycerol might provide better cryoprotection under conditions for freezing pellets of brown trout and Arctic char. 

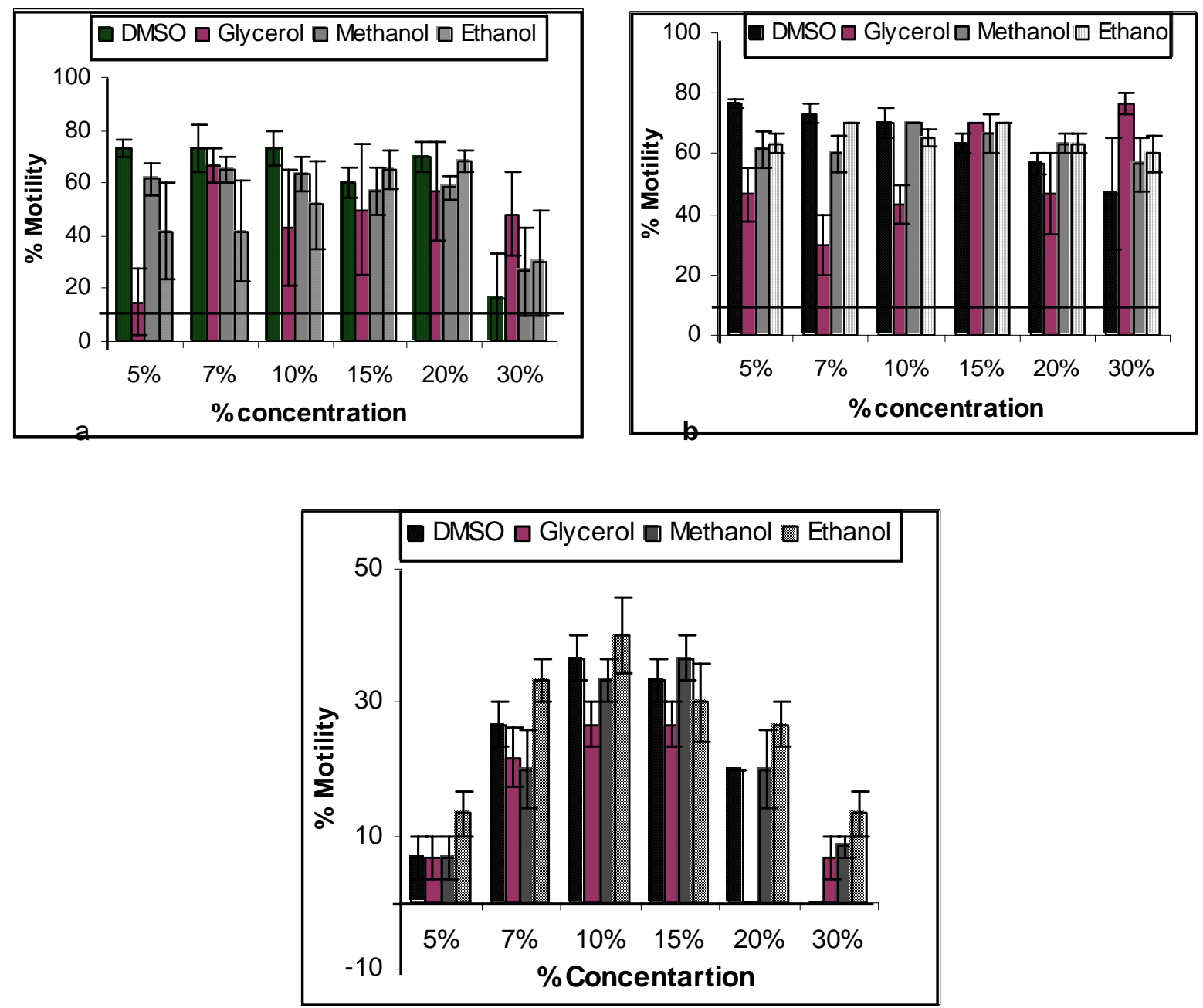

C

Fig.3. Effect of different cryoprotectant concentration on the viability of cryopreserved sperm of $C$. cirrhosus (a) Urea-eggyolk (b) Egg-yolk citrate (c) $0.9 \%$ Nacl each with DMSO, glycerol, ethanol and methabol

\section{Acknowledgement}

The authors would like to thank Bangladesh Agricultural University Research System and Ministry of Science and Information \& Communication Technology for funding the research.

\section{References}

Alam, M.F. 2002. Socioeconomic aspects of carp production and consumption in Bangladesh. In: Penman, D. J., M. G., Hussain, B.J. McAndrew and M.A. Mazid (eds). Proc. Workshop on Genetic Management and improvement strategies for Exotic carps in Bangladesh, BFRI, Mymensingh, Bangladesh, pp. 83-89.

Ali, M.L. 1998. Fishery resources development and management technique. Fish week" 98 compendium. Department of Fisheries, Ministry of Fisheries and Livestock, Government of the peoples republics of Bangladesh, Dhaka, pp. 1-10.

Babiak, I., Glogowski, J., Goryczko, K., Dobosz, S., Kuzminski, H., Strzezek, J. and. Demianowicz, E. 2001. Effect of extender composition and equilibration time of fertilization ability and enzymatic activity of rainbow trout cryopreserved spermatozoa. Theriogenology, $56: 177-192$.

Bergeron, A., Vandenberg, G., Proulx, D., and Bailey, J.L. 2002. Comparison of extenders, dilution ratios and theophylline addition on the function of cryopreserved Walleye semen.Theriogenology 57:1062-1071. 
Chao, N., Chen, H.P. and Chiuliao, I. 1975. Study on cryogenic preservation of Grey mullet sperm. Aquaculture, $5: 389-406$.

Dreanno, C., Suquet, M., Quemener, L., Cosson, J., Fierville, F., Normant, Y. and Billard, R. 1997. Cryopreservation of turbot (Scophthalmus maximus) spermatozoa. Theriogenology, $48: 589-603$.

Eknath, A.E. and Doyle, W. 1990. Effective population size and rate of inbreeding in aquaculture of Indian major carps. Aquaculture, $85: 293-305$.

Gwo, J.C., Strawn, K., Longnecker, M.T. and Arnold. C.R. 1991. Cryopreservation of Atlantic Croaker spermatozoa. Aquaculture, $94: 355-375$.

Harvey, B. and Ashwood-Smith, M.J. 1982. Cryoprotectant penetration and supercooling in the Eggs of Salmonid fishes. Cryobiology, $19: 29-40$.

Hussain, M.G. and Mazid, M.A. 2001. Genetic improvement and conservation of carp species in Bangladesh. Bangladesh Fisheries Research Institute and International Centre for Living Aquatic Resources Management, 74pp.

Kumar, K. 1988. A comparative study of various extenders for cryopreservation of carp spermatozoa. Indian J. Animal Sciences, 58(11): 1355-1360.

Kumar, K. 1989. Studies on cryogenic preservation of carp spermatozoa. Fish Genetics in India, (Eds.) Das \& Jhingram, 199206 pp.

Magyary, I., Dinnyes, A. and Urbanyi, B. 2000. Cryopreservation methods for sperm of the common carp. In: cryopreservation in Aquatic species. Tiersch, T. R. and P. M. Mazik, Editors. World Aquaculture society, Baton Roige, Louisiana. pp. 288-289.

Piironen J. 1993. Cryopreservation of sperm from brown trout (Salmo trutta m. lacustris I.) and Arctic charr (Salvelinus alpinus L.). Aquaculture, $116: 275-285$.

Rana, K.J. and McAndrew, B.J. 1989. The viability of cryopreserved tilapia spermatozoa. Aquaculture, $76:$ 335-345.

Rao, K.G. 1989. Cryopreservation of carp sperm. Fish Genetics in India, 193-198.

Shirohara, J., Canto(Jr.), T. and RImendras, J.M.F. 1982. A comparative study of various extenders for milk fish, Chanos chanos (Forssakal) sperm preservation. Aquaculture, 28 : 339-346.

Withler, F.C. 1982. Cryopreservation of spermatozoa of some freshwater fishes cultured in South and Southeast Asia. Aquaculture, $26: 395-398$. 